TONG ZHU, Ph.D. ${ }^{1}$

(Corresponding author)

E-mail: zhutong@chd.edu.cn

CHANGSHUAI WANG, Master ${ }^{1}$

E-mail: 2017122112@chd.edu.cn

CHENXUAN YANG, Master ${ }^{2}$

(Corresponding author)

E-mail: cyang30@crimson.ua.edu

RUNQING ZHAO, Master ${ }^{3}$

(Corresponding author)

E-mail: runqing.zhao@student.unsw.edu.au

${ }^{1}$ School of Automobile, Chang'an University

Middle-section of Nan'er Huan Road, Xi'an, ShaanXi,

710064, China

2 The Department of Civil, Construction and

Environmental Engineering, The University of Alabama

3013 Cyber Hall, Tuscaloosa, AL 35487, United States

${ }^{3}$ School of Aviation, UNSW Sydney

High St, Kensington, NSW, 2052, Australia
Traffic Engineering

Preliminary Communication

Submitted: 6 Mar. 2019

Accepted: 3 Oct. 2019

\title{
EVALUATION OF EFFECTIVENESS OF SPEED REDUCTION MARKINGS ON DRIVING SPEED IN HIGHWAY TUNNEL ENTRANCE AND EXIT AREAS
}

\section{ABSTRACT}

Tunnels are critical areas for highway safety because the severity of crashes in tunnels tends to be more serious. Controlling vehicle speed is regarded as a feasible measure to reduce the accident rate in the tunnel entrance and exit areas. This paper aims to evaluate the effectiveness of three types of speed reduction markings (SRMs) in tunnel entrance and exit zones by conducting a driving simulation experiment. For this study, 25 drivers completed the driving tasks in the day and night scenarios. The vehicle speed and acceleration data were collected for analysing and the relative speed contrast, time mean speed and acceleration were adopted as indices to evaluate the effectiveness of SRMs. The repeated ANOVA test results revealed that SRMs have a significant effect in reducing vehicle speed, especially in the exit zone. Colour Anti-skid Markings (CASMs) produced a more obvious deceleration in the entrance zone. In the entrance zone, a similar downward trend was performed in the situation of NSRMs and SRMs, but a lower speed occurred in case of SRMs. Besides, CASMs work better and cause an obvious gap of $10 \mathrm{~km} / \mathrm{h}$ in daytime and $5 \mathrm{~km} / \mathrm{h}$ at night compared to the speed without SRMs. In the exit zone, the present study supports the conclusion that the drivers are prone to accelerate. Our results showed that the drivers accelerated in case of NSRMs, while they slowed down in case of SRMs. Thus, SRMs are necessarily implemented in the highway tunnel entrance and exit zones. Our study also indicates that though CASMs result in lower speed at night, the Transverse Speed Reduction Markings (TSRMs) have a better performance than CASMs in daytime. The investigation provides essential information for developing a new marking design criterion and intelligent driver support systems in the highway tunnel zones.

\section{KEY WORDS}

traffic safety; driving behaviour; tunnel; speed reduction markings; simulator study;

\section{INTRODUCTION}

According to the Chinese statistical yearbook (2013), there were approximately 39 million traffic accidents in 2013, which resulted in 65,225 deaths and 254,075 injuries, with a direct economic loss of just over 930 million RMB [1], with the main factors resulting in traffic accidents being speeding, drunk driving and fatigued driving [2]. Tunnels are significant areas for freeway safety as the consequence of accidents being usually severe, though the number of crashes inside is lower than of those outside the tubes [3-5]. The main types of tunnel accidents are rear-end collisions [6-9], crashes into the tunnel wall, rolling over [9] and fire disasters $[4,10,11]$. These accidents could result in significant economic losses and negative social influences 
$[12,13]$. Furthermore, within a tunnel, the accident rates in the entrance and exit zones tend to be higher than in the common segment [7-9, 14]. Reducing the number of accidents in the tunnel entrance and exit zones is crucial to improve the traffic safety associated with tunnels.

For traffic accidents, both the seriousness and probability of accidents are directly proportional to the driving speed [15-19], as the degree of kinetic energy is higher when collision happens. Besides, De Pauw et al. (2014) reported that speeding causes drivers to have less time to react when driving, thus it tends to be unlikely for them to avoid an accident [16]. Similarly, this phenomenon occurs in tunnels. Ma et al. (2009) investigated the characteristics of traffic accidents in Chinese freeway tunnels and stated that accident severity resulting from speeding is marginally higher in freeway tunnels than that in freeway segments [8]. Lu et al. (2014) revealed that the majority of traffic accidents in tunnels resulted from high-speed travel ( $80 \mathrm{~km} / \mathrm{h}$ or more) [9]. Therefore, it is vital to control the speed of vehicles in the entrance and exit zones of the tunnels.
Commonly, Speed Reducing Markings (SRMs) are installed in the tunnel entrance and exit zones to reduce vehicle speed. The Chinese National Standard [20] indicates three types of SRMs, including Transverse Speed Reducing Markings (TSRMs) (Figure 1a), Longitudinal Speed Reduction Markings (LSRMs) (Figure 1b) and Colour Anti-Skid Markings (CASMs) (Figure 2a, 2b). The detailed design patterns of TSRMs and LSRMs are shown in Figure 1 (c, d, e). TSRMs and LSRMs are usually paved on the road, including tunnels, long and steep downgrade segments, horizontal or vertical curves and other sections where the vehicles should decelerate [20], while CASMs are paved in the entrance and exit zones of tunnels to improve the traffic safety [21]. Compared to the Chinese National Standard, the Manual on Uniform Traffic Control Devices introduces some details regarding the design, application, placement, guidance, options and support provisions for SRMs [22] (Figure 2c). It suggests that SRMs should be placed along both edges of the lane, in a pattern of progressively reduced spacing, to create the visual illusion that the drivers are driving faster than the actual speed, thus prompting them to decelerate.

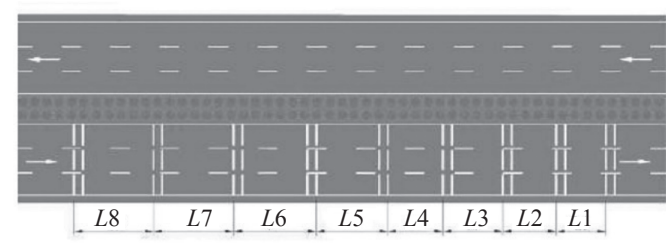

a) TSRMS

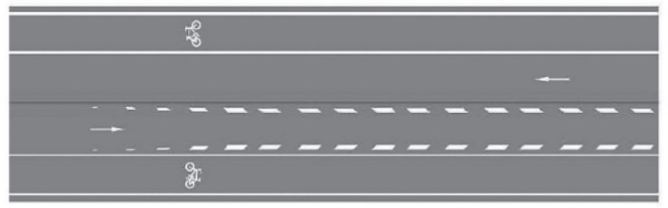

b) LSRMS

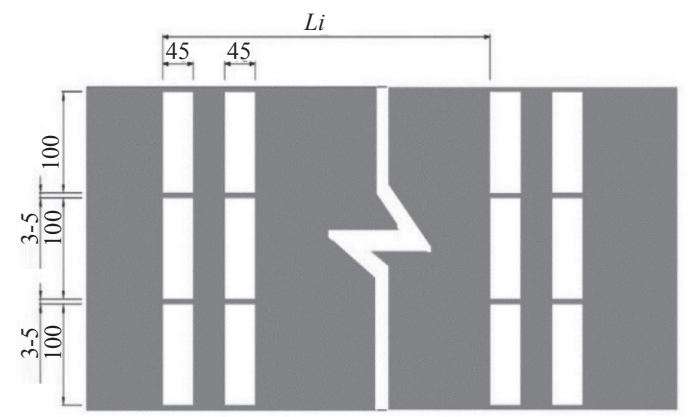

c) Detailed designs of TSRMs [cm]

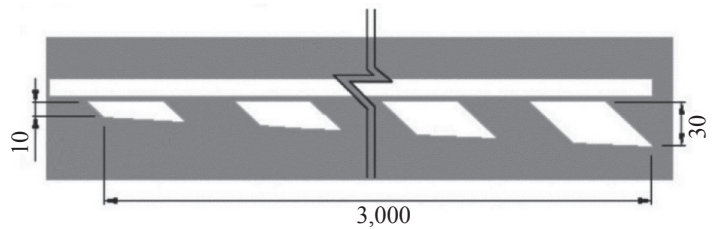

d) Gradual change sections of LSRMs [cm]

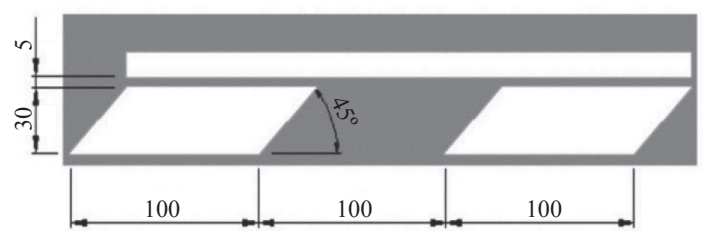

e) Detailed designs of LSRMs [cm]

Figure 1-TSRMs and LSRMs in the Chinese National Standard 

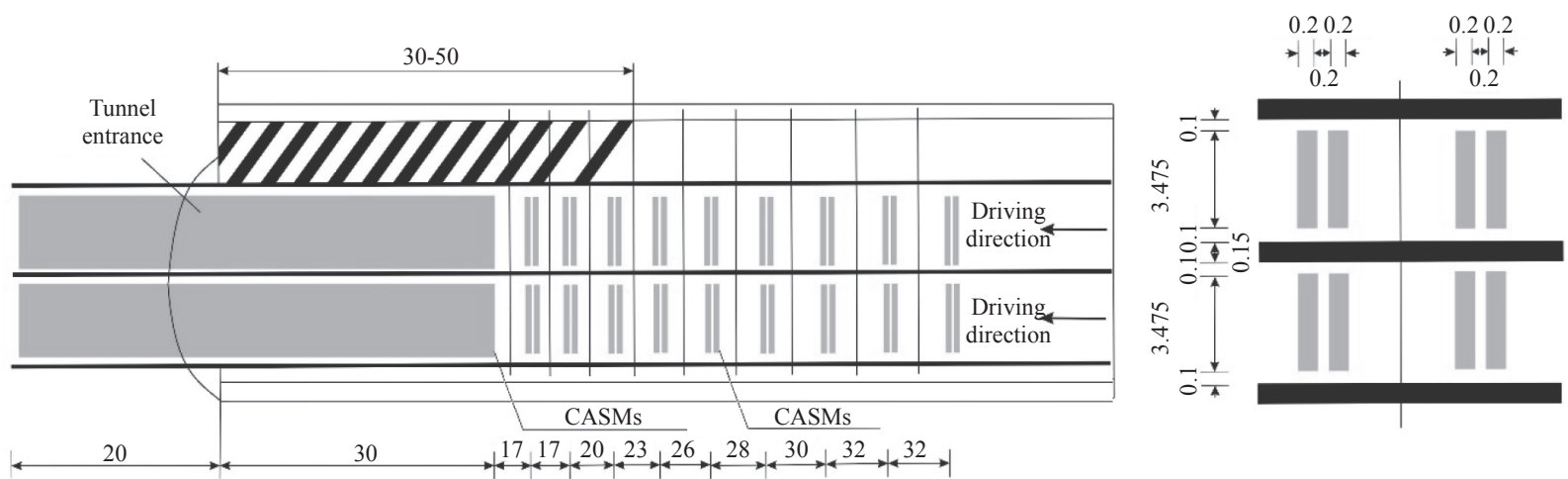

a) Design of CAMSs in the entrance section of tunnels $[\mathrm{m}]$

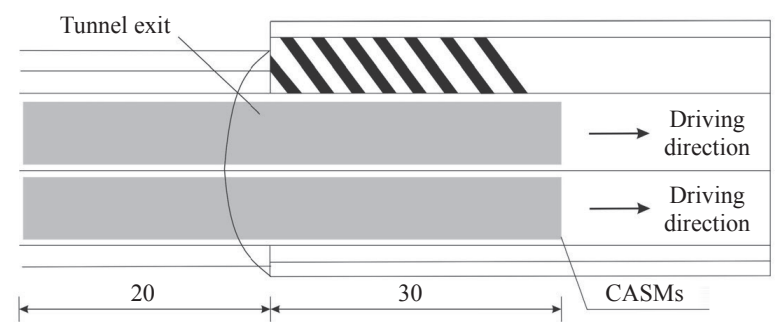

b) Design of CASMs in the exit section of tunnels [m]

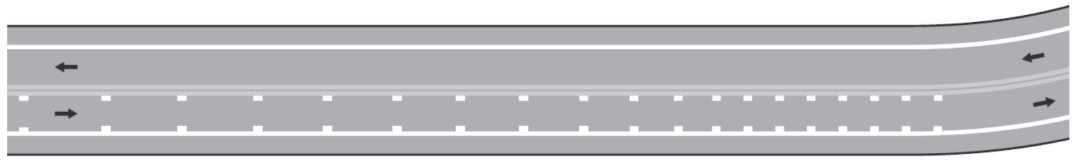

c) Speed Reduction Marking in 2009 MUTCD

Figure 2 - Designs of CASMs in the Chinese National Standard and SRMs in the 2009 MUTCD

The drivers' speed is susceptible to being influenced by SRMs. For example, according to Denton's study (1980), when the distance between adjacent markings is smaller, the drivers are more prone to overestimate their driving speed and take measures to decelerate [23]. Montella et al. (2015) proclaimed that perceptual treatments are the most effective methods to control speed because they can produce significant speed reductions in the approach tangent as well as inside the curve [24]. Ariën et al. (2016) declared that both the transverse rumble strips and herringbone patterns can influence the mean speed and the mean deceleration. Furthermore, transverse rumble strips could generate a more stable speed reduction [25]. Charlton's study (2007) found that the herringbone pavement markings would narrow the effective lane width and promote the deceleration of vehicles when drivers pass a curve [26].

TRSMs, LSRMs, and CASMs can all produce the visual illusions that affect the drivers' speed perception [27-29], or warn the drivers to reduce speed, as well as raise the drivers' vigilance [20]. Through a case study, Ding et al. (2015) reported that TSRMs are effective in the downhill sections with three different vertical grades $(1.5 \%, 2 \%$, and $3 \%$ ), as they can produce the illusion that the vehicle speed is becoming higher than the true speed [15]. Zhao et al. (2018) claimed that LSRMs can be most effective in reducing speed when the radius of the direct connector is $300 \mathrm{~m}$ because LSRMs make the drivers feel that the width of lanes is becoming narrower [30]. In addition, colours can be used to design SRMs, especially yellow, as this brings a sense of brightness and vigilance [31-33]. With colour, CASMs are effective in reducing the accident rate [34], raising the driver's vigilance [31, 32, 35], and increasing the luminance at the tunnel entrance and exit [31]. It could be inferred that SRMs can help drivers to decelerate and improve the traffic safety level when they are paved before the entrance or exit zones of the tunnels.

Although a number of related studies have been conducted to evaluate the effectiveness of SRMs under normal road conditions, there is a lack of research evaluating the effectiveness of SRMs particularly in the entrance and exit zones, as road conditions and sight distance of drivers vary markedly between the outside and the inside of the tunnels 
[36]. Moreover, the drivers' perception of sight differs between the day and night, resulting in drivers having different visibility of SRMs, which may affect the deceleration effect of SRMs. Therefore, it is crucial to evaluate the effectiveness of SRMs in the entrance and exit zones under different light conditions.

Compared with the implementation of research in real terms, the simulation research is easier and cheaper [37]. By using the driving simulators, different variables can be controlled, and interferential factors may be isolated. Therefore, simulation was implemented in this study.

This research aims to evaluate the effectiveness of SRMs through investigating the driver's speed with simulators in freeway tunnels under different light conditions. There are different simulated scenarios where LSRMs, TSRMs, and CASMs are set respectively. The results and data from the simulations will be collected and analysed. According to the driving behaviours from the data, the effectiveness of SRMs in the entrance and exit zones will be evaluated. If SRMs are effective, the results of this research would show an obvious difference in the driving speed between SRMs and Non-SRMs (NSRMs) experiments.

\section{METHODOLOGY}

The subject drivers were selected from the volunteers with full driver licenses and more than three years of driving experience. A total of 30 volunteers recruited from Yan Ta District of Xi'an participated in these experiments, consisting of 21 males and 9 females. The structure of participants is specially designed since the ratio between male and female drivers is 7:3 in China [27]. However, five participants, two females and three males included, suffered from 3D vertigo of driving simulator and did not complete the formal experiments. The rest of twenty-five participants successfully finished the experiments, and their age ranged from 23 to 40 (mean=28.6; $\mathrm{SD}=4.38$ ). All of them had a normal or corrected-to-normal vision. They allegedly had a valid driving license with at least three years of driving experience (mean=8.7; $\mathrm{SD}=5.26)$ and drove at least once a month. In addition, all the drivers had enough sleep before the experiments and were experienced in driving in freeway tunnels.

This study launched a driving-simulated experiment by using UC-win/road software to establish the freeway tunnel models. The driving simulator
(Figure 3) was used to collect the real-time data, including operation data of vehicles (speed, acceleration, etc.) and manoeuver data (gears, clutch, accelerator, brake, etc.) of subjects. The data acquisition frequency of the driving simulator was $30 \mathrm{~Hz}$. The visual scenario was projected onto three large screens, providing a $130^{\circ}$ field of vision.

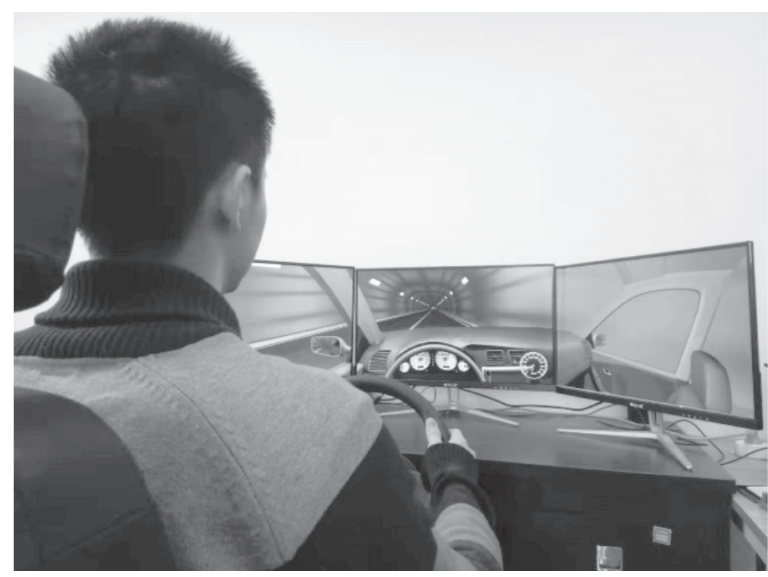

Figure 3 - Driving simulator

In this research, three types of SRMs which are TSRMs, LSRMs, CASMs, were studied. According to the Chinese National Standard [20, 21], the detailed designs of the three types of SRMs are shown in Figure $1(c, d, e)$ and Figure $2(a, b)$. Since the drivers may have different reflections on SRMs in day and at night, this experiment designed two scenarios for the day (Scenario I) and night (Scenario II). Each scenario was composed of two-lane road segments and four tunnels equipped with lights on the top. The speed limit was $100 \mathrm{~km} / \mathrm{h}$ for the freeway segment, whereas $80 \mathrm{~km} / \mathrm{h}$ for the tunnel sections with speed limit signs [38]. These tunnels are examples taken from the tunnel groups in Shaanxi province, China. In both scenarios, each type of SRMs was randomly paved once before the entrance and exit zones of three tunnels. The left tunnel was used as the control group in the NSRMs experiment. The beginning and ending point of SRMs conforms to the Chinese National Standards [20, 21]. The simulated scenes are as shown in Figure 4. According to the Chinese Technical Standard of Highway Engineering [39], the freeway roads were built with two lanes in a single direction, and the design speed ranged from $60 \mathrm{~km} / \mathrm{h}$ to $100 \mathrm{~km} / \mathrm{h}$. In addition, the right lane is used for driving, while the left lane provides the traffic flow. The width of a single lane is $3.75 \mathrm{~m}$. According to the Chinese Guidelines for the 


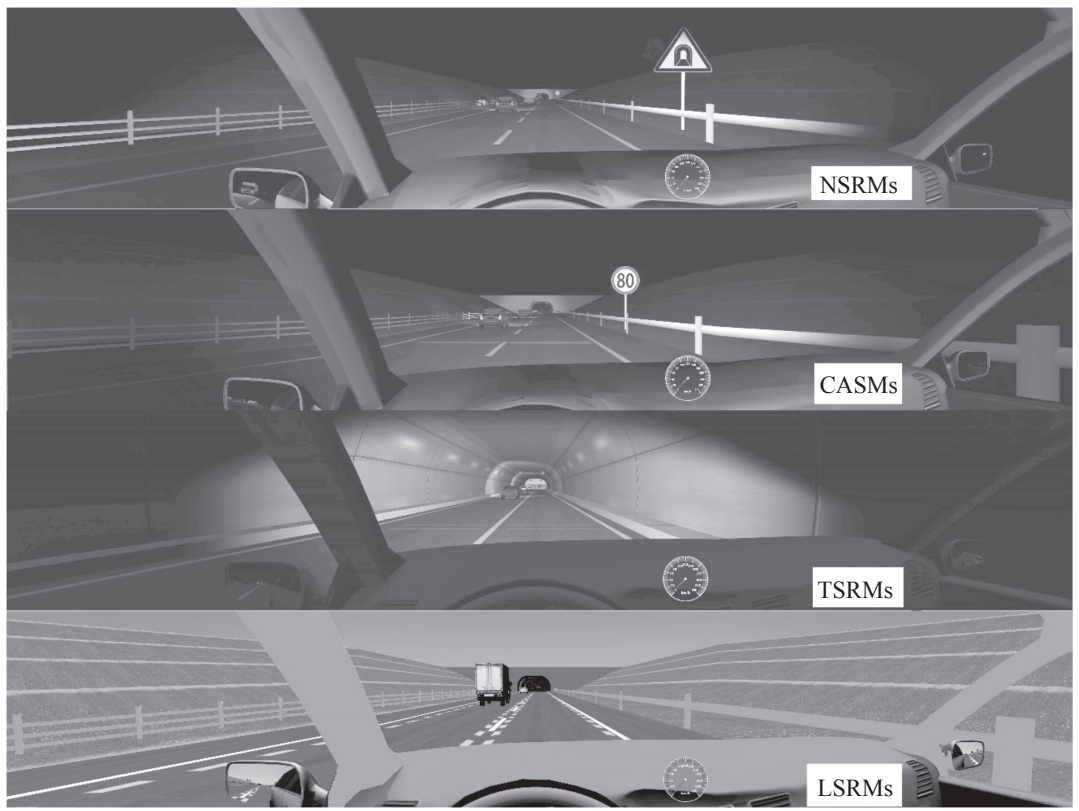

Figure 4 - Simulated scenes with different SRMs

Design of Highway Tunnels [40], the two directions of tunnels are separated. The length is $1 \mathrm{~km}$ for each tunnel, and the construction gauge height is $5 \mathrm{~m}$.

Relative speed contrast $(\delta)$, spot speed $(v)$ and mean acceleration $(M a)$ were extracted from the simulation data and employed as the dependent variables in this study.

Relative speed contrast $(\delta)$ shows the overall speed deceleration in the tunnel entrance and exit zones $[15,30,41]$

$\delta=\frac{v_{E}-v_{S}}{v_{S}}$

where $v_{S}$ is the speed when the front end of the car reaches the start point of the SRMs, $v_{E}$ is the speed when the front end of the car reaches the end of the SRMs. Positive $\delta$ shows an overall trend of acceleration in the zone, while negative $\delta$ means the deceleration. Spot speed ( $v$ ) is the vehicles' spot speed when they pass a certain spot before the entrance and the exit. Mean acceleration $(M a)$ is the average of the vehicles' acceleration while they travelled through the entrance and exit zones.

The participants were required to complete a questionnaire about their basic information (age, gender, driving experience) when they arrived at the driving simulation laboratory. Then they were introduced to the experiment process. However, they were not informed of the research objective of the experiment. In addition, all of them signed up an informed consent form. Before the experiment, the participants were guided on how to use the driving simulator in detail, including the steering wheel, pedal, brakes, and the gear lever. Moreover, participants received at least 10 minutes of training to become familiar with the operation of the driving simulators. The vehicle speed could be seen from the speedometer. After a break of three minutes, the participants began to conduct the formal experiments. The participants completed both the day and night scenarios once each. The computer randomly selected which of the scenarios to present first. During the driving procedure, the participants were required to drive in the right lane, and they were not allowed to change. The participants were required to obey the traffic rules during the simulations. After each driving scenario, the participants had a rest break for three minutes, and the entire driving experiment took approximately 25 minutes. The operation data of vehicles and participants were recorded by the UC-win/road software. The participants who completed the experiments successfully were paid $100 \mathrm{RMB}$ as a reward.

\section{RESULTS}

In this section, the extracted data were analysed, adopting the descriptive statistical method and inferential statistics method. A repeated measure analysis of variance (ANOVA) was conducted with a significance level of 0.05 by using SPSS (version 20). Before performing AVOVA, K-S (Kolmogorov-Smirnov) test and Levene's test were used to verify the normality and homogeneity of 
variances for the data, which showed that all data were normally distributed and the homogeneity of variances was satisfied.

\subsection{Relative speed contrast}

The total speed drop (or speed up) trend can be reflected by relative speed contrast in the entrance and exit zones of the tunnels.

For the entrance, the maximum relative speed contrast (with the mean value of -0.084 in scenario I and -0.082 in scenario II) appears in the situation of NSRMs, while the minimum relative speed contrast (with mean value of -0.110 in scene I and -0.106 in scene II) appears in CARMs paved section (Table 1). Generally, deceleration in the daytime was slightly higher than the one at night. A repeated measure analysis of variance (ANOVA) was conducted to examine the overall effect of SRMs on the relative speed contrast. The non-significant main effect of SRMs setting conditions was found. Even so, rel- ative speed contrast for SRMs was slightly smaller than that for NSRMs in both scenarios, which means that SRMs provide some assistance to decreasing driving speed in the entrance zone of the tunnel.

In the exit zone, the drivers accelerated only in cases of NSRMs (with the mean value of 0.027 in scenario I, and 0.026 in scenario II), and the minimum relative speed contrast (with mean value of -0.026 in scenario I, and -0.019 in scenario II) occurred in CASMs paved sections (Table 1 and Figure 5).

ANOVA was conducted to examine the effectiveness of SRMs. The main effect of SRMs was significant $\left(\mathrm{F}_{(3.96)}=3.035 ; \mathrm{P}=0.0329<0.05\right.$ in scenario $\mathrm{I}$ and $\mathrm{F}_{(3.96)}=3.040 ; \mathrm{P}=0.0327<0.05$ in scenario II), indicating that the driving speed was decreased in the SRMs paved sections. However, there is no significant difference between the two scenarios for a certain type of SRMs ( $>0.05)$ in the post-hoc comparisons.

Table 1 - Relative speed contrast for SRMs

\begin{tabular}{||c|c|c|c|c|c||}
\hline \multirow{3}{*}{ Section } & \multicolumn{2}{|c|}{ Scenario I (Daytime) } & \multicolumn{2}{c|}{ Scenario II (Night) } & \multirow{2}{*}{ SRMs } \\
\cline { 2 - 6 } & Mean & S.D. & Mean & S.D. & LSRMs \\
\hline \hline \multirow{3}{*}{ Entrance section } & -0.110 & 0.060 & -0.106 & 0.063 & CASMs \\
\cline { 2 - 6 } & -0.089 & 0.080 & -0.086 & 0.070 & TSRMs \\
\cline { 2 - 6 } & -0.097 & 0.083 & -0.091 & 0.067 & NSRMs \\
\cline { 2 - 6 } & -0.084 & 0.083 & -0.082 & 0.056 & LSRMs \\
\hline \multirow{3}{*}{ Exit section } & -0.013 & 0.049 & -0.015 & 0.055 & CASMs \\
\cline { 2 - 6 } & -0.026 & 0.054 & -0.019 & -0.064 & TSRMs \\
\cline { 2 - 6 } & -0.013 & 0.085 & -0.014 & 0.072 & NSRMs \\
\cline { 2 - 6 } & 0.027 & 0.069 & 0.026 & 050 &
\end{tabular}

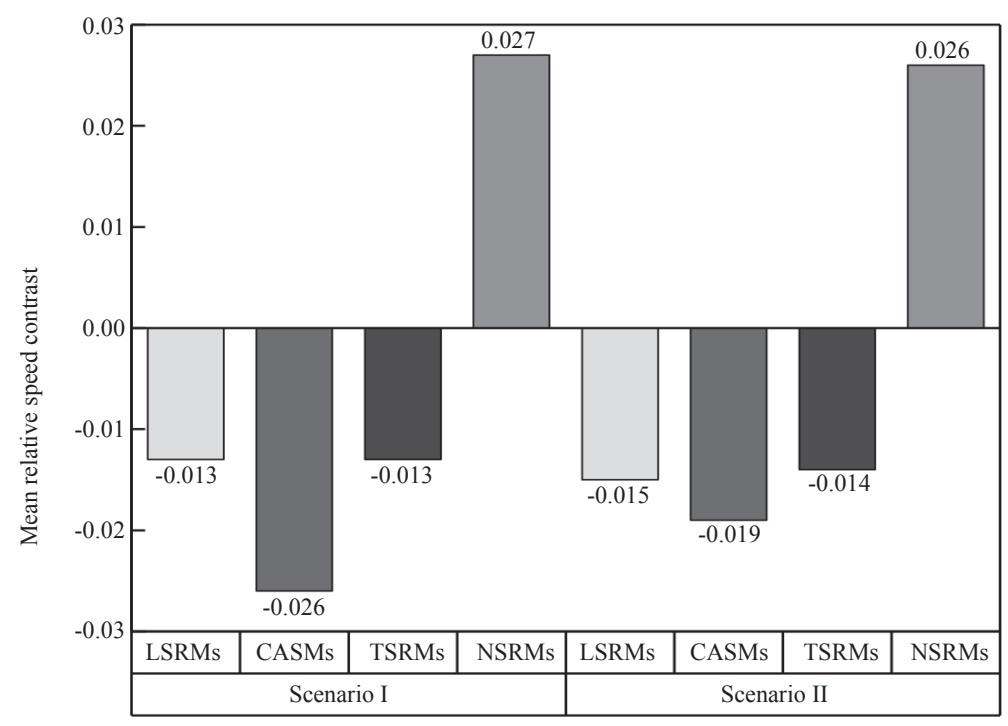

Figure 5 - Relative speed contrast in the tunnel exit zone 


\subsection{Spot speed}

The vehicle operation speed before the entrance and at the exit under the influence of SRMs can be represented by spot speed.

For the entrance zone, spot speed for NSRMs decreased from $91.01 \mathrm{~km} / \mathrm{h}$ (500 m before the entrance) to $77.57 \mathrm{~km} / \mathrm{h}$ (at the entrance) in daytime, but it was higher than that for SRMs in each observed position before the entrance. For CASMs, it shows the same decreasing trend, but $v$ was the smallest among SRMs (Table 2 and Figure 6a). In case of night, spot speed for NSRMs was higher than that for SRMs in each observed point, and it decreased from $89.99 \mathrm{~km} / \mathrm{h}(500 \mathrm{~m}$ before the entrance) to $79.14 \mathrm{~km} / \mathrm{h}$ (at the entrance) gradually. Generally, spot speed for SRMs was lower than the one for NSRMs. Spot speed for CASMs was also the smallest one in the three types of SRMs throughout the entire entrance section (Table 2 and Figure 6).

Table 2 - Spot speed in the entrance zone and ANOVA test results

\begin{tabular}{|c|c|c|c|c|c|c|c|}
\hline & \multirow{2}{*}{$\begin{array}{c}\text { Detecting point } \\
\text { (before the entrance) }\end{array}$} & \multirow{2}{*}{ LSRMs } & \multirow{2}{*}{ CASMs } & \multirow{2}{*}{ TSRMs } & \multirow{2}{*}{ NSRMs } & \multicolumn{2}{|c|}{ ANOVA } \\
\hline & & & & & & $\mathrm{F}$ & $\mathrm{P}$-value \\
\hline \multirow{11}{*}{ 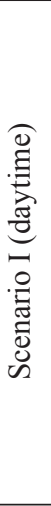 } & 500 & 88.45 & 81.27 & 83.36 & 85.43 & 2.819 & 0.043 \\
\hline & 450 & 87.42 & 81.46 & 82.96 & 87.42 & 2.981 & 0.035 \\
\hline & 400 & 87.62 & 84.93 & 85.37 & 91.01 & 3.001 & 0.034 \\
\hline & 350 & 85.21 & 82.92 & 84.61 & 89.16 & 3.611 & 0.016 \\
\hline & 300 & 84.11 & 82.28 & 84.05 & 89.46 & 3.252 & 0.025 \\
\hline & 250 & 82.47 & 79.18 & 81.85 & 85.37 & 3.426 & 0.020 \\
\hline & 200 & 78.41 & 78.02 & 78.86 & 83.44 & 2.771 & 0.046 \\
\hline & 150 & 77.48 & 76.22 & 77.12 & 81.03 & 2.867 & 0.041 \\
\hline & 100 & 75.14 & 74.77 & 76.17 & 79.89 & 3.031 & 0.033 \\
\hline & 50 & 73.38 & 73.44 & 74.94 & 78.45 & 3.401 & 0.021 \\
\hline & 0 & 72.56 & 72.34 & 73.32 & 77.57 & 3.263 & 0.025 \\
\hline \multirow{11}{*}{ 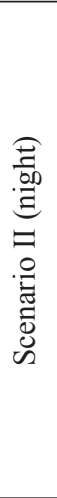 } & 500 & 86.60 & 85.09 & 86.83 & 89.99 & 2.861 & 0.041 \\
\hline & 450 & 86.89 & 84.24 & 86.08 & 89.70 & 2.884 & 0.039 \\
\hline & 400 & 86.41 & 84.33 & 85.77 & 89.48 & 2.752 & 0.047 \\
\hline & 350 & 86.21 & 83.15 & 85.64 & 88.88 & 2.816 & 0.042 \\
\hline & 300 & 86.04 & 83.29 & 84.86 & 88.51 & 2.961 & 0.036 \\
\hline & 250 & 84.83 & 80.57 & 82.58 & 86.63 & 4.118 & 0.008 \\
\hline & 200 & 83.43 & 79.44 & 79.81 & 85.43 & 3.520 & 0.018 \\
\hline & 150 & 80.81 & 76.28 & 77.17 & 83.39 & 2.750 & 0.046 \\
\hline & 100 & 79.26 & 75.19 & 76.72 & 81.53 & 4.509 & 0.005 \\
\hline & 50 & 77.68 & 73.58 & 74.49 & 80.46 & 3.653 & 0.015 \\
\hline & 0 & 75.54 & 73.48 & 74.89 & 79.14 & 4.449 & 0.006 \\
\hline
\end{tabular}

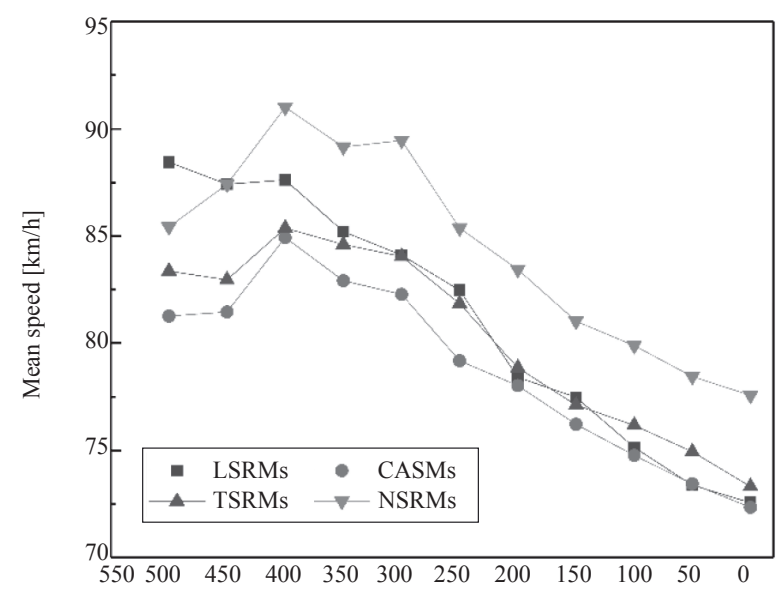

a) Scenario $I$

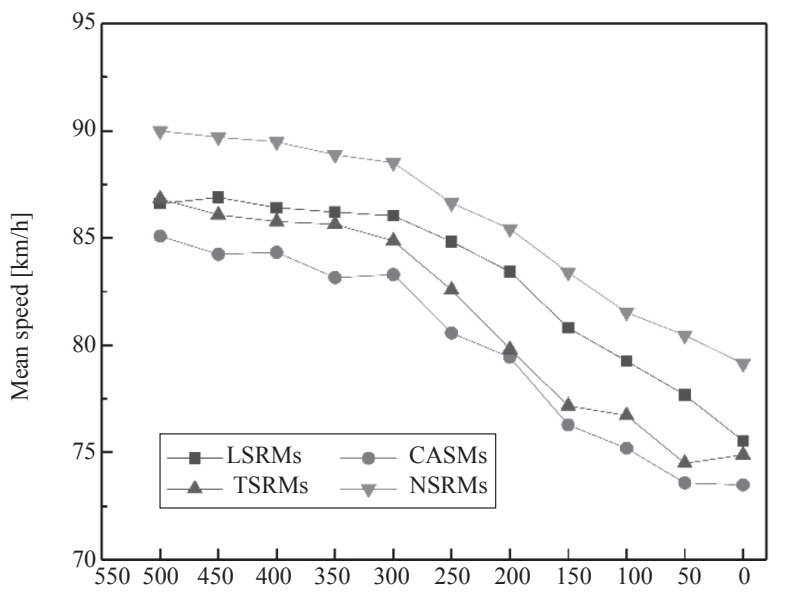

b) Scenario II

Figure 6-Spot speed before the tunnel entrance 
The ANOVA test for spot speed at each observed point was conducted to evaluate the effectiveness of SRMs in the entrance zone (Table 2). The main effect of SRMs was significant $(<0.05)$ at each detecting point.

In the exit zone, the changing trend of spot speed was different from that in the entrance zone. In case of daytime, spot speed for NSRMs increased from $72.31 \mathrm{~km} / \mathrm{h}(500 \mathrm{~m}$ before the exit) to $79.22 \mathrm{~km} / \mathrm{h}$ (at the exit), while for TSRMs there was gradual decrease from $75.02 \mathrm{~km} / \mathrm{h}$ to $73.00 \mathrm{~km} / \mathrm{h}$. For LSRMs, spot speed fluctuated near $74.5 \mathrm{~km} / \mathrm{h}$, while for CASMs it appeared as a decreasing trend. In case of night, spot speed for NSRMs fluctuated between $74 \mathrm{~km} / \mathrm{h}$ and $75 \mathrm{~km} / \mathrm{h}$ in the section from $500 \mathrm{~m}$ to $250 \mathrm{~m}$ before the exit, but considerable increases occurred at $250 \mathrm{~m}$ before the exit. Spot speed for CASMs presented an obvious decrease throughout the observed section. Spot speed for TSRMs was the lowest among SRMs before the observed point at $200 \mathrm{~m}$, but for CASMs it becomes the lowest at the observed point at $150 \mathrm{~m}$.
Furthermore, the ANOVA test for spot speed at each observed point was conducted to evaluate the effectiveness of SRMs in the exit zone (Table 3). The result indicated that the main effect of SRMs was significant $(<0.05)$ at each detecting point.

\subsection{Mean acceleration}

From Table 4 and Figure $8 a$, the results for the entrance zone can be concluded. Generally, mean acceleration was negative, which means that the driving speed decreases in two scenarios. This was accorded with the results drawn from the mean relative speed contrast. For SRMs, the mean acceleration was lower than -0.1 in scenario II, and the one for TSRMs was the smallest $(-0.1121)$ in all situations. For the case of daytime, the mean acceleration for CASMs was smaller (-0.1224) than in other situations. The most points of the mean acceleration were below the zero-reference line, and that meant that the majority of participants had taken a decelerating manipulation, resulting in the reduction of the driving speed. For NSRMs, the mean acceleration

Table 3 - Spot speed and ANOVA results in the exit zone

\begin{tabular}{|c|c|c|c|c|c|c|c|}
\hline & \multirow{2}{*}{$\begin{array}{l}\text { Detecting point } \\
\text { (before the exit) }\end{array}$} & \multirow{2}{*}{ LSRMs } & \multirow{2}{*}{ CASMs } & \multirow{2}{*}{ TSRMs } & \multirow{2}{*}{ NSRMs } & \multicolumn{2}{|c|}{ ANOVA } \\
\hline & & & & & & $\mathrm{F}$ & P-value \\
\hline \multirow{11}{*}{ 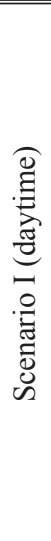 } & 500 & 74.30 & 77.26 & 75.02 & 72.31 & 3.470 & 0.019 \\
\hline & 450 & 74.46 & 77.19 & 74.98 & 73.38 & 2.907 & 0.029 \\
\hline & 400 & 75.43 & 77.00 & 74.66 & 74.27 & 3.056 & 0.032 \\
\hline & 350 & 75.09 & 76.30 & 74.53 & 76.33 & 2.850 & 0.041 \\
\hline & 300 & 74.49 & 76.21 & 74.00 & 77.10 & 2.809 & 0.044 \\
\hline & 250 & 74.79 & 76.29 & 73.81 & 77.19 & 2.908 & 0.039 \\
\hline & 200 & 74.65 & 76.15 & 73.70 & 78.21 & 3.357 & 0.022 \\
\hline & 150 & 75.05 & 76.05 & 73.49 & 78.36 & 3.357 & 0.022 \\
\hline & 100 & 74.73 & 75.62 & 73.40 & 78.61 & 3.166 & 0.028 \\
\hline & 50 & 75.46 & 75.16 & 73.10 & 79.06 & 2.937 & 0.037 \\
\hline & 0 & 74.73 & 74.58 & 73.00 & 79.22 & 3.456 & 0.019 \\
\hline \multirow{11}{*}{ 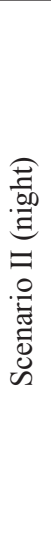 } & 500 & 73.35 & 74.55 & 71.48 & 74.08 & 3.310 & 0.023 \\
\hline & 450 & 73.88 & 73.25 & 71.09 & 73.85 & 2.719 & 0.048 \\
\hline & 400 & 73.12 & 72.77 & 70.77 & 74.83 & 3.056 & 0.032 \\
\hline & 350 & 74.26 & 72.54 & 71.70 & 74.53 & 3.847 & 0.012 \\
\hline & 300 & 74.69 & 72.13 & 71.82 & 74.89 & 3.265 & 0.025 \\
\hline & 250 & 74.79 & 72.05 & 72.05 & 74.26 & 3.552 & 0.017 \\
\hline & 200 & 74.37 & 71.85 & 71.52 & 74.72 & 2.774 & 0.046 \\
\hline & 150 & 74.57 & 71.57 & 72.16 & 75.70 & 3.449 & 0.019 \\
\hline & 100 & 74.94 & 71.37 & 71.81 & 76.25 & 4.101 & 0.009 \\
\hline & 50 & 74.69 & 71.09 & 71.35 & 76.62 & 2.809 & 0.042 \\
\hline & 0 & 73.62 & 70.75 & 71.04 & 76.76 & 2.731 & 0.048 \\
\hline
\end{tabular}



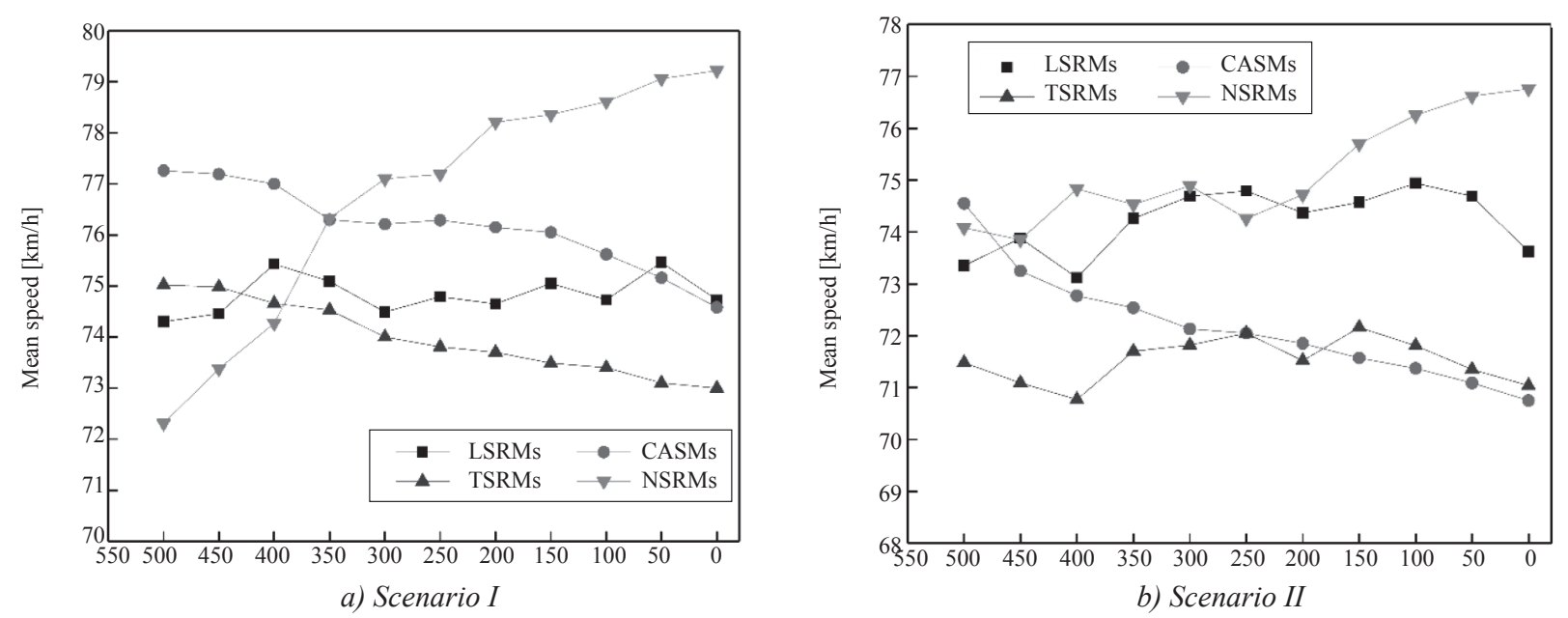

Figure 7 - Spot speed before the tunnel exit

Table 4-Mean acceleration in the entrance and exit zones

\begin{tabular}{||c|c|c|c|c|c||}
\hline \multirow{3}{*}{ Zones } & \multicolumn{2}{|c|}{ Scenario I } & \multicolumn{2}{c||}{ Scenario II } & \multirow{2}{*}{ SRMs } \\
\cline { 2 - 6 } & Mean & S.D. & Mean & S.D. & LSRMs \\
\hline \hline \multirow{4}{*}{ Entrance zone } & -0.0984 & 0.197 & -0.1033 & 0.211 & CASMs \\
\cline { 2 - 6 } & -0.1244 & 0.198 & -0.1087 & 0.200 & TSRMs \\
\cline { 2 - 6 } & -0.0862 & 0.230 & -0.1121 & 0.166 & NSRMs \\
\cline { 2 - 6 } & -0.0761 & 0.218 & -0.0659 & 0.190 & LSRMs \\
\hline \multirow{5}{*}{ Exit zone } & -0.0099 & 0.152 & -0.0080 & 0.104 & CASMs \\
\cline { 2 - 6 } & -0.0771 & 0.138 & -0.0767 & 0.115 & TSRMs \\
\cline { 2 - 6 } & -0.0145 & 0.142 & -0.0222 & 0.138 & NSRMs \\
\cline { 2 - 6 } & 0.0402 & 0.129 & 0.0321 & & \\
\hline
\end{tabular}

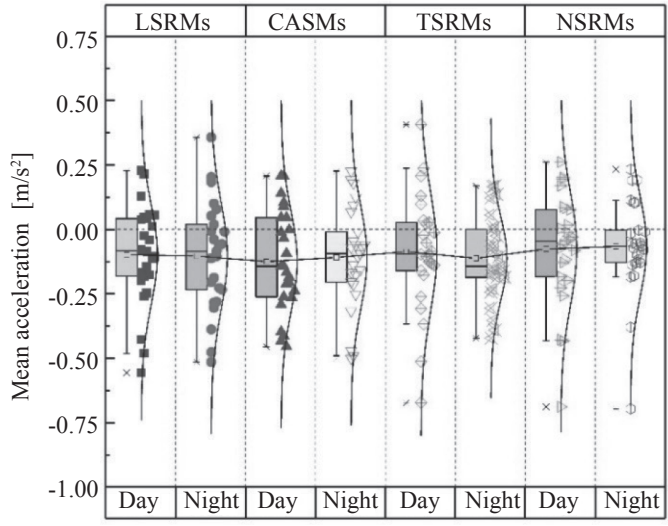

a) Mean acceleration in the entrance zone

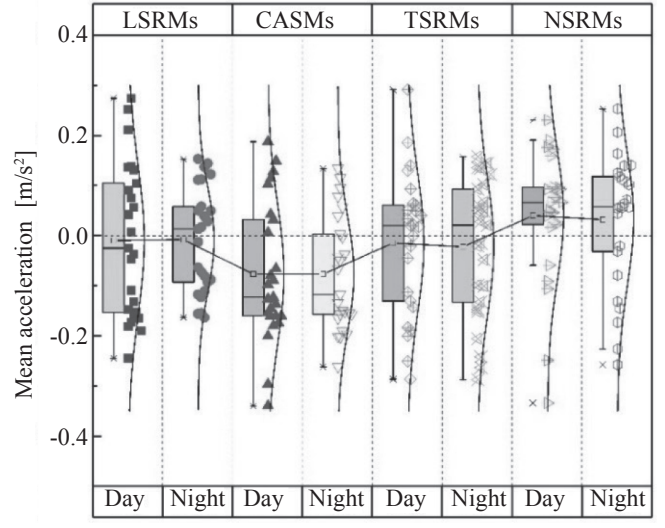

b) Mean acceleration in the exit zone

Figure 8 - Mean acceleration distribution in the tunnel entrance and exit zones

was the largest in all cases, which meant that the drivers took a relatively slight decelerating manipulation.

The ANOVA test was applied to evaluate if SRMs had a significant effect on driver's deceleration in the entrance zone of the tunnels. The results showed no significant difference in two scenarios $\left(\mathrm{F}_{(3.96)}=0.244\right.$; $\mathrm{P}=0.865>0.05$ in Scenario $\mathrm{I}$ and $\mathrm{F}_{(3.96)}=0.3016$;
$\mathrm{P}=0.824>0.05$ in Scenario II). Neither is there any significant difference between the two scenarios ( $>00.05$ ).

For the exit zone, it was obvious that the mean acceleration was negative for SRMs. The smallest value (with the mean value -0.0771 in scenario I and -0.0767 in scenario II) was in the CASMs paved sections, while the mean acceleration for NSRMs is 
positive ( 0.0402 in scenario I and 0.0321 in scenario II). Moreover, the mean acceleration for LSRMs was slightly bigger than that for TSRMs. For CASMs, the majority of mean acceleration points were below the zero-reference line, while those for NSRMs were above the zero-reference line. The mean acceleration for LSRMs and TSRMs presented a symmetrical distribution near the zero-reference line.

Then the ANOVA test was conducted to examine the SRMs effect on the driver's deceleration. Significant effects were found in the exit zone of tunnels $\left(\mathrm{F}_{(3.96)}=2.927 ; \mathrm{P}=0.0377<0.05\right.$ in scenario $\mathrm{I}$ and $\mathrm{F}_{(3.96)}=3.325 ; \mathrm{P}=0.0229<0.05$ in scenario II).

\section{DISCUSSION}

Previous studies have shown that drivers need to invest more effort to adapt to the changing light environment due to "the black hole effect" of tunnels. Thus, they are prone to take decelerating manoeuver to achieve a safer feeling, while they approach the tunnels [36]. The present study confirms the findings that the drivers took deceleration as a mitigation strategy in the entrance zones.

In the entrance zones, the driving speed had a noticeable difference in the situation of NSRMs and SRMs. Previous studies reported that speeds were significantly affected by SRMs [27-29]. In this study, a similar downward trend has performed in the situation of NSRMs and SRMs, but a lower speed occurred in case of SRMs. Our results are consistent with the perceptual treatment research that suggests that TRSMs, LSRMs, and CASMs can raise the drivers' vigilance [20] and increase the drivers' perceptual speed. In this case, the drivers are more prone to decelerate after overestimation. Besides, CASMs worked better and caused an obvious gap of $10 \mathrm{~km} / \mathrm{h}$ in the daytime and $5 \mathrm{~km} / \mathrm{h}$ at night, compared to the speed without SRMs. A similar finding was reported in the previous literature, that CASMs are effective in reducing the accident rate [34], raising the driver's vigilance [31, 32, 34, $35]$, and increasing the luminance in the tunnel entrance and exit zones [31].

In the exit zone, the present study supports the conclusion that the drivers are prone to accelerate [38]. These results suggest support for the driver's perception hypothesis, that low illuminance and semi-closed characteristics of tunnels may depress the drivers and make them want to leave the tunnel as soon as possible.
It has also been shown that SRMs have a significant effect on speed deceleration in the exit zone, which had also been proven in the research by Ding et al. (2015) [15]. Our results showed that the drivers accelerated in case of NSRMs, while they slowed down in case of SRMs. Thus, SRMs are necessarily implemented in the highway tunnel exit zones. Our study also indicates that though CASMs result in lower speed at night, TSRMs perform better than CASMs in daytime. A possible explanation is that TSRMs are paved with horizontal bar markings which get more attention and increase cognitive vigilance better than CASMs as they have no horizontal bar in the exit zone as shown in Figure $2 b$. Future research may provide more evidence to confirm this hypothesis.

Although there is rather extensive literature on the proposed to evaluate the effectiveness of SRMs in a variety of road conditions, the speed reductions effect of SRMs is found to be insufficient in the entrance and exit zones of the tunnels. This study provides some of the first evidences to examine the effectiveness of the proposed recommendations for the engineering applications.

A limitation of this research is the longitudinal slope of the simulated road in zero degrees. However, in reality, the freeway tunnels usually have longitudinal slopes. Tunnels with longitudinal slopes need to be simulated in a further study. Another limitation of the present study is based on the driving simulator. Future research based on road testing would provide more evidence to improve the design criteria and propose the driver support systems.

\section{CONCLUSION}

The aim of this study is to investigate the effectiveness of SRMs in the tunnel entrance and exit zones by conducting a driving simulation experiment. It was found that SRMs do have a significant effect in speed reduction both in day and night scenarios. Besides, the Colour Anti-Skid Markings (CAMs) are recommended for the implementation in the highway tunnel entrance zones in order to reduce speeding. The results of the investigation have enhanced our understanding of the driving behaviour and the effectiveness of SRMs in the tunnel entrance and exit zones. Our findings also provide important information for the development of new marking design criteria and the driver support systems in the tunnel zones. 


\section{ACKNOWLEDGEMENTS}

This research is supported financially by the $\mathrm{Na}-$ tional Natural Science Foundation of China (No. 51178054).

朱䑣, 王长帅, 杨晨煊, 赵润青

高速公路隧道出入口段减速标线应用效果研究

摘要:

与其他路段相比, 发生在隧道内的事故后果更加 严重, 因此, 隧道是高速公路安全重点区域。车速 控制是降低隧道出入口段事故率的有效措施。论文 旨在通过驾驶模拟实验评估三种减速标线 $(S R M S)$ 在隧道出入口段应用的有效性。25位驾驶人完成了 白天和夜晚场景的模拟驾驶实验。对车辆速度和加 速度数据进行分析, 采用相对速度变化比、平均速 度和平均加速度作为评价 $S R M S$ 有效性的指标。方 差分析结果表明, SRMS 具有显著的降速效果, 彩 色防滑减速标线 $(C A S M S)$ 在隧道出口段效果更为 明显。在隧道入口段, 无标线 (NSRMS) 情况下 和设置 $S R M S$ 情况下虽然车速降低趋势相似, 但在 应用 $S R M S$ 的情况下车速更低, $C A S M S$ 的减速效果 更好, 在白天和夜晚场景下产生的速度差分别为 $10 \mathrm{~km} / \mathrm{h} 、 5 \mathrm{~km} / \mathrm{h}$; 在隧道出口段, 驾驶人在 $N S R M \mathrm{~s}$ 情况下加速, 在 $S R M S$ 情况下则减速。因此, 有必要 在公路隧道出入口段设置 $S R M S$ 。本研究还表明, $C A S M s$ 在夜晚情况下可以导致更低的车速, 但在白 天纵向减速标线 $(T S R M S)$ 的减速效果要优于 $C A S M s$ 。 本研究为建立新的公路隧道区域标线设计规范和智 能驾驶辅助系统提供了必要的理论依据。

\section{关键词:}

交通安全; 驾驶行为; 隧道; 减速标线; 驾驶模拟器研究

\section{REFERENCES}

[1] National Bureau of Statistics of China. China statistical yearbook 2013; 2013.

[2] Ding H, Zhao X, Rong J, et al. Experimental research on the effectiveness of speed reduction markings based on driving simulation: A case study. Accident Analysis \& Prevention. 2013;60: 211-218.

[3] Kircher K, Ahlstrom C. The impact of tunnel design and lighting on the performance of attentive and visually distracted drivers. Accident Analysis \& Prevention. 2012;47: 153-161.

[4] Carvel R, Marlair G. A history of fire incidents in tunnels; 2005.

[5] Lemke K. Road safety in tunnels. Transportation Research Record. 2000;1740(1): 170-174.

[6] Zhong D, Pan L, Tian Q. Studies on the characteristics of traffic accidents in expressway tunnels. Geo-China. 2016;2016: 109-116.

[7] Cornelia N. Comparative Analysis of Safety in Tunnels.
Young Researchers Seminar; 2007.

[8] Ma Z, Shao C, Zhang S. Characteristics of traffic accidents in Chinese freeway tunnels. Tunneling and underground space technology. 2009;24(3): 350-355.

[9] $\mathrm{Lu} \mathrm{L}, \mathrm{Lu}$ J, Xing Y, et al. Statistical analysis of traffic accidents in Shanghai River crossing tunnels and safety countermeasures. Discrete Dynamics in Nature and Society. 2014;1740: 1-7.

[10] Kirkland CJ. The fire in the channel tunnel. Tunneling and underground space technology. 2002;17(2): 129-132.

[11] Leitner A. The fire catastrophe in the Tauern Tunnel: experience and conclusions for the Austrian guidelines. Tunneling and Underground Space Technology. 2001;16(3): 217-223.

[12] Barth U. Managerial and technical aspects of tunnel safety regarding normal and emergency mode. Proceedings of the international conference tunnel safety and ventilation. 2002;8: 8-10.

[13] Mashimo H. State of the road tunnel safety technology in Japan. Tunneling and Underground Space Technology. 2002;17(2): 145-152.

[14] Ni HL, Dai YH, Zhao QX. Research on distribution characteristics of traffic accidents in expressway tunnel. Highway. 2010;4: 126-129.

[15] Ding H, Zhao X, Rong J, et al. Experimental research on the effectiveness and adaptability of speed reduction markings in downhill sections on urban roads: a driving simulation study. Accident Analysis \& Prevention. 2015;75: 119-127.

[16] De Pauw E, Daniels S, Thierie M, et al. Safety effects of reducing the speed limit from $90 \mathrm{~km} / \mathrm{h}$ to $70 \mathrm{~km} / \mathrm{h}$. Accident Analysis \& Prevention. 2014;62: 426-431.

[17] Allpress JA, Leland Jr LS. Reducing traffic speed within roadwork sites using obtrusive perceptual countermeasures. Accident Analysis \& Prevention. 2010;42(2): 377383.

[18] Kazemzadeh K, Dasoomi MH. The Role of Speed Reduction Model in Urban Freeways Tunnels Accidents. ICTTE 2015: International Conference on Transportation and Traffic Engineering; 2015.

[19] Lee SJ. The speed review: road environment, behaviour, speed limits, enforcement and crashes. Report, 1993.

[20] Standardization Administration of the People's Republic of China. Road Traffic Signs and Markings (GB57682009). Beijing; 2009. Chinese.

[21] JTG D81-2006. Design Guidelines for Freeway Safety Facilities. Beijing; 2017. Chinese.

[22] Federal Highway Administration. Manual on uniform traffic control devices; 2009.

[23] Denton GG. The influence of visual pattern on perceived speed. Perception. 1980;9(4): 393-402.

[24] Montella A, Galante F, Mauriello F, et al. Effects of traffic control devices on rural curve driving behaviour. Transportation Research Record: Journal of the Transportation Research Board. 2015;(2492): 10-22.

[25] Ariën C, Brijs K, Ceulemans W, et al. The effect of pavement markings on driving behaviour in curves: A driving simulator study. Transportation Research Board $91^{\text {st }}$ Annual Meeting. 2012. 19 p.

[26] Charlton SG. The role of attention in horizontal curves: 
A comparison of advance warning, delineation, and road marking treatments. Accident Analysis \& Prevention. 2007;39(5): 873-885.

[27] Wan H, Du Z, Yan Q. The speed control effect of freeway tunnel sidewall markings based on colour and temporal frequency. Journal of Advanced Transportation. 2016;50(7): 1352-1365.

[28] Shi X, Du Z, Zhou L, et al. Optimization of Deceleration Markings of Visual Illusion in a Freeway Tunnel. Journal of Freeway \& Transportation Research \& Development. 2016;10(4): 63-70.

[29] Wan H, Du Z, Yan Q, et al. Evaluating the effectiveness of speed reduction markings in highway tunnels Transport. 2018;33(3): 647-656.

[30] Zhao X, Ding H, Lin Z, et al. Effects of longitudinal speed reduction markings on left-turn direct connectors. Accident Analysis \& Prevention. 2018;115: 40-52.

[31] Xu M, Pan X, Deng Q. Setting method of thin-layer antiskid coloured pavement in tunnel based on increasing luminance of pavement. CICTP 2012: Multimodal Transportation Systems-Convenient, Safe, Cost-Effective, Efficient; 2012. p. 3073-3083.

[32] Yuan H, Xiao G, Nie L, et al. Discussion on the Relation of Colour and Traffic Safety. Industrial Safety \& Environmental Protection; 2006.

[33] Xia Z, Lv Y, Pan X, et al. Research on design pattern of city tunnel side wall based on the driver visual effect. In: Stanton N, Landry S, Di Bucchianico G, Vallicelli A. (eds) Advances in Human Aspects of Transportation. Advances in Intelligent Systems and Computing, vol 484. Springer, Cham; 2017. p. 689-701.
[34] Haack A. Fire protection in traffic tunnels: general aspects and results of the EUREKA project. Tunneling and underground space technology. 1998;13(4): 377381.

[35] Lie H, Zhang Z, Guo D, et al. Research progress and prospect of application technology of thin-layer antiskid coloured pavement at home and abroad. International Conference on Electric Technology and Civil Engineering (ICETCE). IEEE; 2011. p. 2557-2560.

[36] Ma Y, Fu R. Research and development of drivers' visual behaviour and driving safety. China J Highway Transp. 2015;28(6): 82-94.

[37] Underwood G, Crundall D, Chapman P. Driving simulator validation with hazard perception. Transportation Research Part F: Traffic Psychology \& Behaviour. 2011;14(6): 435-446.

[38] Zheng Z, Du Z, Yan Q, et al. The impact of rhythm-based visual reference system in long highway tunnels. Safety Science. 2017;95: 75-82.

[39] Technical Standard of Freeway Engineering. Professional standard of the People's Republic of China; 2014. Chinese.

[40] Guidelines for Design of Freeway Tunnels. Professional standard of the People's Republic of China; 2004.

[41] Ding H, Zhao X, Ma J, et al. Evaluation research of the effects of longitudinal speed reduction markings on driving behaviour: A driving simulator study. International Journal of Environmental Research and Public Health. 2016;13(11): $15 \mathrm{p}$.

[42] Martindale A, Urlich C. Effectiveness of transverse road markings on reducing vehicle speeds. NZ Transport Agency research report 423, 2010. 